\title{
IDENTIFICAÇÃO E ATUALIZAÇÃO GEOGRÁFICO DE LOCAIS IDENTIFICADOS E PRODUZIDOS PELA COMISSÃO DE MELHORAMENTO DO RIO SÃO FRANCISCO.
}

\author{
Fernanda de Jesus Novais ${ }^{1}$; Ivoneide de Franca Costa ${ }^{2}$ \\ 1. Bolsista PIBIC/CNPq, Graduando em Engenharia Civil, Universidade Estadual de Feira de Santana, e-mail: \\ nanda novais15@hotmail.com \\ 2. Ivoneide de França Costa, Departamento de Letras e Artes, Universidade Estadual de Feira de Santana, e-mail: \\ $\underline{\text { neidefc@uefs.br }}$
}

PALAVRAS-CHAVE: Melhoramentos; Mapas; Navegação.

\section{INTRODUÇÃO}

Os melhoramentos do sistema de navegação fluvial, aliado ao ferroviário e portuário, fariam parte da necessidade do governo imperial em criar vias de locomoção para o transporte de mercadorias e pessoas. Para tal era necessário o conhecimento dos rios e dos dois sistemas em pontos estratégicos.

Para atender a demanda de reformas foram organizadas comissões, uma delas foi a Comissão de Melhoramento do Rio São Francisco (CMRSF) 1883-1896. A CMRSF foi criada para executar melhorias no Rio Com objetivo de facilitar a navegação e por em prática os melhoramentos do rio a partir dos estudos feitos pela $\mathrm{CHI}$ (Comissão Hidráulica do Imperio ). A comissão foi composta por engenheiros brasileiros aproveitando, inclusive, alguns que trabalharam na CHI. A primeira equipe foi chefiada pelo Antonio Plácido Peixoto do Amarante com a participação dos engenheiros Theodoro Fernandes Sampaio, João Emiliano Amarante, Evaristo Galvão Filho, João Felix Peixoto de Azevedo Sobrinho, Themístocles Pompeu de Albuquerque Figueiredo, Brotero Frederico de Macedo Costa, Antônio Julio de Gouvêa, além do médico Guilherme Lassance Marback.

A história dos mapas é mais antiga que a própria história, isto se pensarmos na história como a documentação escrita sobre fatos passados. A confecção de mapas precede a escrita. Isto pode ser concluído como fato comprovado, por muitos exploradores dos vários povos primitivos que, embora eles não houvessem alcançado a fase da escrita, desenvolveram habilidades de traçar mapas.

O objetivo da cartografia consiste em reunir e analisar dados e medidas das diversas regiões da terra, e representar graficamente em escala reduzida os elementos da configuração que possam ser claramente visíveis. Para pôr em evidência a configuração da superfície terrestre, o instrumento principal do cartografo é o mapa.

Os mapas escolhidos para tal pesquisa têm características similares. Feitos à mão por Theodoro, num papel de linhas horizontais e verticais, representam respectivamente paralelos meridianos. Os mapas traziam os detalhamentos e as orientações necessárias à implementação técnica dos projetos propostos. 


\section{MATERIAL E MÉTODOS OU METODOLOGIA (ou equivalente)}

Pesquisa bibliográfica para identificação dos mapas utilizados pela comissão de melhoramento do Rio São Francisco. Tal pesquisa foi realizada na documentação pertencente ao projeto de pesquisa ao qual o plano se vincula. Para complementar a pesquisa também foi feito estudos em outras fontes bibliográficas e a utilização do google maps e a tecnologia para atualizar mapas foi de total importância para identificar esses locais atualmente.

\section{RESULTADOS E/OU DISCUSSÃO (ou Análise e discussão dos resultados)}

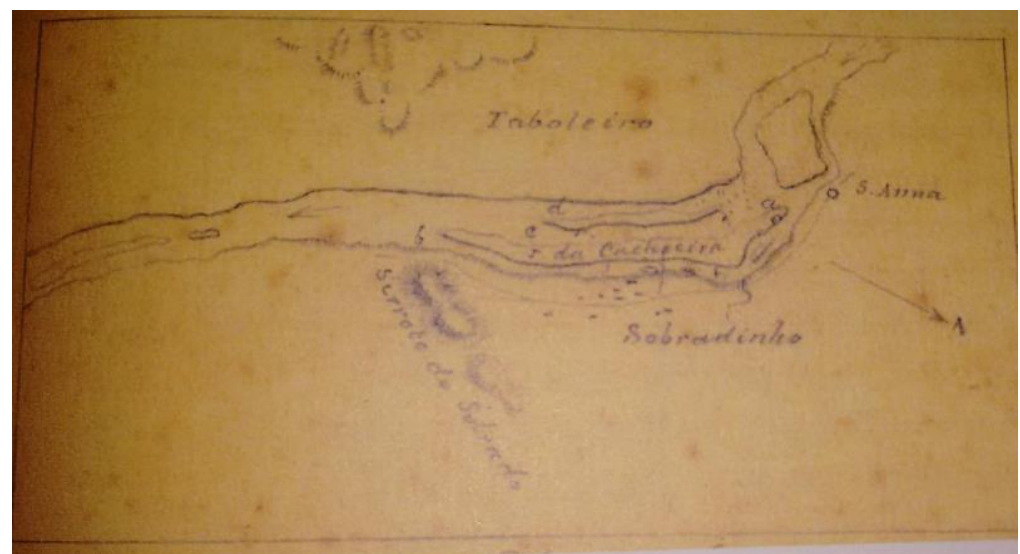

Figura 1: Mapa da cachoeira de Sobradinho. (Fonte: IGBHB,1879).

Na figura 1, temos a localização do canal do sobradinho localidade onde houve melhoramentos importantes para a região, um deles foi a construção do reservatório de Sobradinho, tão importante para a segurança do suprimento de energia ao Nordeste, que na época era um sistema isolado do resto do país, gerou impactos socioambientais de porte. O reservatório de Sobradinho, cuja barragem se localiza $50 \mathrm{Km}$ a montante da cidade de Juazeiro, na Bahia, inundou terras de sete municípios: Casa Nova, Sento Sé, Pilão Arcado e Remanso, que tiveram as suas sedes transferidas e foram bastante afetados; e mais Juazeiro, Xique-Xique e Barra, que sofreram menos impactos. Foram retiradas da área a ser alagada cerca de 70 mil pessoas, das quais $80 \%$ era composta por camponeses que abasteciam o mercado regional. A população se concentrava nas margens do rio, nas férteis planícies de aluvião, nas ilhas do Rio São Francisco e deixavam despovoadas as áreas de caatinga, pois a terra é arenosa, seca, pobre em nutrientes e, portanto, não ofereciam boas condições para plantio. Com a construção da barragem, a maior parte da população ribeirinha foi deslocada compulsoriamente pelo Estado e reassentada a vários quilômetros das margens originais do rio, em plena caatinga, em solos impróprios para o plantio. Com a formação do lago desapareceram as melhores terras para a agricultura nas condições sociais de produção até então vigentes. 


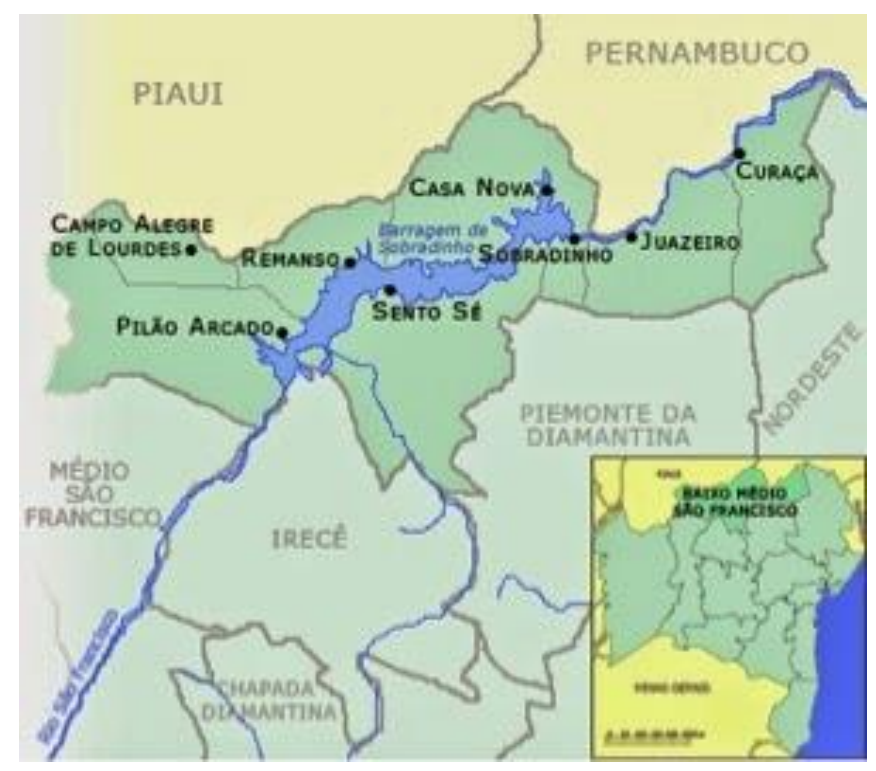

Figura 2: Barragem do Sobradinho e cidades atingidas. (Arquivo Sindicato dos Trabalhadores de Sento-Sé, 1977).

As obras tinham o caráter de intervenção no rio, modificando o seu curso. O impacto ambiental das modificações não era questão de discussões na época. Hoje, uma obra semelhante não teria apoio de órgãos de defesa ambiental e nem da opinião pública.

De fato, pelo que se percebeu da documentação, houve a melhora da navegação, pois permitiu que outros tipos de embarcações, além das balças e barcas, pudessem navegar pelo trecho. Entretanto, a inserção de outros tipos de modelos de embarcações vai além dos melhoramentos: envolve avanços tecnológicos que são disseminados em todo mundo, mesmo em regiões consideradas remotas.

As intervenções no rio ainda acontecem, agora com o nome de transposição, cujo objetivo é desviar as águas do rio São Francisco para outros Estados.

\section{CONSIDERAÇÕES FINAIS (ou Conclusão)}

A importância dos mapas é, sem dúvidas, a localização e indicação. Por meio deles, podemos encontrar qualquer ponto da superfície terrestre e deslocar-nos até ele. É claro que são necessários mapas especificamente voltados para esse intuito. Os mapas confeccionados por Theodoro tiverem sua grande contribuição para que os melhoramentos fossem possíveis, seus detalhamentos das informações de acordo com o trajeto na inserção de maior número de elementos de reconhecimento da territorialidade e controle dos espaços onde as descobertas refletiam a expansão e exploração.

\section{REFERÊNCIAS}

ANRJ. 5F 564, maço 147, documento $\mathrm{n}^{\circ}$. 1. ANRJ. 5F 564, maço 146. Relação dos materiais da extinta Comissão de Melhoramento do Rio São Francisco entre a Diretoria da Estrada de Ferro de São Francisco.

COSTA, Ivoneide de França, História das ciências e Imagem: expedição pelo Rio São Francisco e a Chapada Diamantina e os desenhos de Theodoro Sampaio. In: $10^{\circ}$. 
TECNOLOGIA. 2005. Anais... Belo Horizonte: UFMG, 2005.

COSTA, Ivoneide de França Costa. Comissão Hidráulica do Império (1879-1880): profissionalização e técnica a serviço dos melhoramentos no século XIX. Tese (Doutorado em História das Ciências) - Programa de Pós-Graduação em História das Ciências e das Saúde - COC - Fiocruz, Rio de Janeiro. 2013, 270p.

MENEZES, Paulo Marcio Leal de. Vamos falar de mapas? In: Boletim da Sociedade de Cartografia, 2004.n.53.p.2.

RAISZ, Erwin Josephus. Cartografia geral. Rio de Janeiro: Cientifica, 1969. 414p.

SANTA, Cruz. Pequena Revista de Religião, Letras, Artes e Pedagogia. 1901, 1902. Escola Typografica Salesiana do Lyceu do Sagrado Coração, São Paulo: v. 1.

TELLES, Pedro Carlos da Silva. História da engenharia no Brasil. Rio de Janeiro: Livros Técnicos e Científicos, 1984.

De Professora de Geografia: Disponível em: professoradegeografia.blogspot.com/2014/.../texto-de-apoio-para-1s-series-situacao.ht... Acesso em Julho 2018.

De Alunos online: Importância dos mapas: Disponível em: https://alunosonline.uol.com.br/geografia/importancia-dos-mapas.html. Acesso em Julho 2018. 